\title{
O pensamento sociológico de Bergson
}

Candido Motta Filho

Em sua vida, consagrada sempre aos problemas fundamentais, Bergson mostrou, num traçado nítido, a curva luminosa de seu pensamento. O detentor do prêmio de matemática de 1877, que se impõe, lógo em seguida, no curso da literatura, inicia seu sucesso de pensador com um trabalho de psicologia: "Essais sur les données immediates de la conscience" e escreve sua obra de velhice, dentro do campo social. Começa pelos problemas do conhecimento para, afinal, chegar à teoria do procedimento.

Mantendo sua espantosa lucidez, a-pesar-de atormentado pela moléstia, Bergson procura estudar o comportamento humano em razão da coexistência social. O seu último livro não teve a repercussão que se esperava. O conferencista sensacional da Sorbonne, que atraía os homens de ciência e o elemento elegante de Paris, agora é um velho reumático, que perdeu o contato com o mundo, que, por sua vez, se transformou violentamente. A sociologia revolucionária, que se apresentava nos debates acadêmicos, agora vive na prática, a custa de experiências sangrentas. O intuicionismo de Bergson era visivelmente preferido pelo revolucionismo racional, provindo de MARx e de Sorel.

A filosofia de ação, que preconizára, tornára-se uına realidade, além do que fôra previsto. Em 1933, quando saiu o seu livro "Les sources de la morale et de la religion", o 
problema não podia ser mais da ação em si, mas da ação agindo. Bergson tinha diante dos olhos. um mundo transformando-se.

Por muito tempo, a sua obra filosófica, debatida, mas sempre sugestiva, parecia oferecer uma lacuna, por não cuidar da moral e da religião, principalmente porque os filósofos, que provinham do iluminismo, procuravam sempre enfrentar êsse assunto. O mundo cultural moderno sentia a poderosa influência moral de Rousseau e de Kant. Preocupado com a teoria do conhecimento, com os problemas atinentes ao instinto e à inteligência, com o homem fabricante de utensílios, BERGSON não se afastava da interioridade humana, não no sentido kanteano, mas no típico sentido de energia espiritual.

Entretanto, a vida lhe foi sempre exigente. Não era possivel que, numa época de transformações radicais da sociedade, onde a crise de valores tomava aspetos alarmantes, BERgSon continuasse com esse inexplicavel espaço em branco, na obra que tanta repercussão tinha tido.

Não bastava que BERGSON compreendesse o individualmente humano, mas tambem a coexistência social e assim tambem o socialmente humano. Na grande guerra, o cientista puro toma posição em favôr do pensamento francês. Aliás, já em 1911, numa conferência que pronunciou em Birminghan, aludia ao assunto. Dizia então que os grandes homens de bem são os reveladores de verdades metafísicas, porque, conforme sua sedutora comparação, "o fogo que está no centro da terra não aparece senão na boca dos vulcỗes" ("L’Énergie spirituelle", página 26).

Depois, tendo feito parte do jury do Sena, não se negou a dar aos jornalistas que o procuravam, sua opinião sobre o problema do crime. Tinha observado então atitudes sociais, isto é, tinha analisado o comportamento do jurado em face de um réu. Naquele instante, o que predominava, não devia predominar. Bergson ficava verdadeiramente chocado com o que via. O jurado resolvia arrastado pelo instinto e, com isso, creava situações perigosas. BERGson 
receitava um remédio para atenuar essa situação: - os jurados deveriam motivar, por escrito, o seu julgamento. 0 simples fato de escrever o pensamento, obrigá-los-ia a aplicar o elemento lógico, que decorre da inteligência e da vida social.

Não havia, propriamente, uma novidade no pensamento bergsoneano, pois o que ele dizia, a propósito do juri, estava na própria construção de sua obra. Thibaudet dizia que, entre a sua cosmologia e a sua psicologia, um discipulo de Bergson podia ensaiar uma sociologia (1).

Propriamente, porém, o mestre não tratou do assunto, que era apenas usado e não estudado. Essa diferença é notada principalmente agóra quando se verifica o desenvolvimento de uma filosofia social, o gosto pela etnologia, pela ciência dos costumes, pelas ciências políticas, pela sociologia enfim.

Bergson era mais um fornecedor de argumentos do que um sociólogo argumentando. Seu mobilismo filosófico, sua doutrina do "élan vital", sua teoria sobre a memória, sua maneira de encarar a evolução creadora e a energia espiritual constituíam um riquissimo material para as investigações sociológicas. Bergson foi, ainda, no tempo da "Évolution Créatrice", um dos mais sugestivos pensadores para a sociologia e para a política, chegando mesmo alguem a dizer que Bergson é o filósofo consequente do predomínio de uma estrutura liberal. O próprio Sonel se dizia discipulo de Bergson.

Nesse sentido, basta um exame superficial sobre o pensamento francês do fim do século desenove e começo do século vinte. Não é só Durkheim, Tarde, Levy Bruhl, mas Banés, Maurras, Peguy, Boutroux, Massis, Bouglé, Deat e tantos outros que afirmam e negam, quasi todos contaminados pelo bergsonismo (2).

(1) Thibaudet - "Le bergonisme", vol. II, pág. 158.

(2) Massis - "Les jeunes gens d'aujourd'hui". 
Como lembra Gilbert Maire, néssa época o bergsoneano Massis abandona suas idéias para acompanhar MaUrRas e Alfred de TARde, para acompanhar Bergson abdica das antigas influências de Maurras (3).

Levando uma vida quasi reclusa, BERGSon considerava suas idéias políticas e sociais insuficientes, e elas poderiam existir, talvês, como sua influência na música de Debussy !

Seu ensáio sobre o riso não deixa, entretanto, de ser, em última analise, um ensáio sociológico. $O$ riso, que corrige certas atitudes do espírito, decorre, por sua vez, de uma situação social. "As cerimônias, escreve BERGSon, representam, no corpo social, aquilo que o corpo representa para o corpo individual; elas devem o sentido grave que representam ao fáto de se identificarem a objétos dignos de respeito e perdem essa gravidade desde que a imaginação as isóla" ("Le rire", pág. 40).

Bergson não só analisa o significado individual, psicológico do riso, mas, alargando esse significado, coloca o fenômeno para ser examinado no campo social. "O riso, diz ele, é purameute humano, volta-se para a inteligência pura e só se refere ao homem em sociedade" RabELAIs dizia que o riso é próprio do homem. Mas, cumpre acrescentar que o homem só ri de seu semelhante. Nem o animal, nem a natureza provocam riso. O macaco provoca-o por aproximar-se do homem. O cão provoca o riso, quando obedece a uma vontade ou a um plano do homem. $O$ riso, que representa uma fôrça da natureza e, principalmente, uma fôrça da inteligência, é, acima de tudo, um fenômeno social. $\mathrm{O}$ homem só ri entre os homens. Aquele que ri sózinho é ridículo. Daí o riso nos grupos, o riso nas assembléias, nos teatros, o "risus scholasticus", manifestações grupais e não individuais. Para Bergson, o riso é "une grimade sociale" Pelo exame do fenômeno do riso, poderiamos dizer como os antigos: - "castigat ridendo mores".

O problema social, principalmente, em certos aspetos, não póde deixar de fazer parte do corpo de um sistema

(3) Gilbert MaIre - "Bergson, mon maître" 
filosófico. Platão e Ariśóteleses davam, nesse sentido, o melhor exemplo do pensamento helênico. E esse exemplo, seguido através dos séculos, facilitou a Augusto Comte a sistematização primeira da sociologia, como ciência da sociedade.

A filosofia de Bergson, tocando acidentalmente nos problemas sociais, aparecia com um espaço em branco, dando a muitos a impressão de que o mestre opuzesse a psicologia à sociologia.

Bergson dava mesmo a impressão de pensar, a maneira de certos filósofos para quem, "no fundo do poço da conciência, é que residiria toda metafísica" (4).

Não seria BERGSon um adversário da sociologia? O sẹ sistema, em si mesmo, não seria uma oposição à análise sistematizada dos fenômenos sociais?

Fôra o positivismo o aparelhador da sociologia. Seu objeto seria o estudo metódico das condições exteriores dos sêres humanos num meio social e levaria a convicção de que a vida é uma expressão desse meio. Bergson celebrizára-se na Sorbonne, mostrando a riqueza do mundo interior e os novos horisontes da psicologia.

Augusto Comte, que pretendia a reforma da humanidade, que apelava para a sociologia a fim de auxiliar a reconstrução social, - não colocava a psicologia em sua classificação das ciências,bem como não admitia a introspecção como método de investigação científica.

Durkheim, entregue, de corpo e alma, ao positivismo científico, creador de um método próprio para a sociologia, não ocultava seu desdém pelas investigações de ordem psicológica, propícias a levar a inteligência a caprichosas conclusões metafísicas.

Durk heIm não só se refere aos males das prenoções como procura conceituar os fatos sociais como algo objetivo, "comme des choses" Assim, o autor das "Règles de la Méthode sociologique" mostra, a todo instante, os perigos

\footnotetext{
(4) Bouglé - "Bilan de la sociologie française contemporaine", 1938.
} 
do subjetivismo para afirmar que a ciência do fato social só é, efetivamente ciência, quando explica o homem pela exterioridade que o envolve.

Bergson seria assim o oposto de tudo isso. Ele seria um adversário de Durkheim, pois, na expressiva fráse de Búuglé, "convida-nos quebrar os gêlos dos conceitos de origem social, para alcançar a água corrente da vida interior" (2). Além disso, surgia, no Colégio de França, com incomparavel prestígio, como sucessor de Gabriel Tarde, que se levanta, em estudos que fizeram época, contra Emme DURKHEIM.

Para TARDE, a vida social é uma decorrência da vida psíquica. Todas as atividades e relações coletivas decorrem da imitação. Crenças, rituais, instituições, obrigações, desejos propagam-se dentro de uma certa unanimidade de indivíduo a indivíduo (6). Ha entre os homens um poder de contaminação psíquica; ha, explicando os fenômenos sociais, uma inter-psicologia.

Como Bergson salta esse capítulo precioso da cultura humana? Propriamente não salta, mas por ele passa apenas para quebrar os gêlos e deixar ver, na profundeza, a perene corrente do mundo interior.

Porém, o seu espírito que viveu intensamente os problemas fundamentais da vida, não podia continuar assim. Investigações interessantíssimas se faziam para demonstrar a projecçã̃o do social no individual. Manifestações de ordem política, de ordem patogênica como o suicídio, de ordem expressional, como a palavra, a mímica, o gesto, danças, cantos,ornatos, regras de conduta e de culto, tabús e mitos, a técnica, o confôrto, a cultura, evidenciam a existência não só de uma psicologia coletiva, como tambem de uma influência, perfeitamente sensível, do clima social sôbre a alma do indivíduo.

(5) Bouglé, ob. cit., pág. 29.

(6) G. TARDE, "Les lois de l'Imitation" 
Bergson não se refere a esse aspeto da obra de Spencer, quando analisa e critica o seu evolucionismo. Não se impressiona com Quatrepagues e Letourneau. Não discutiu o imenso progresso da etnologia, nem opôs qualquer objeção às afirmativas da sociologia alemã e americana. De vez em vez, faz referências generalizadas aos processos de vida social, e precisamos caminhar com cuidado, de lapis em punho, para assinalar as páginas em que Bergson estende suas meditações sôbre o problema sociológico. Mas, depois, a vida chamou repetidamente a sua atenção, e na sua obra de velhice, mantendo sempre o seu espírito radinso, Bergson traça seu pensamento social.

"Les deux sources de la morale et de la religion" é um livro de um espírito sem par que chegou a plenitude, sem que tivesse a repercussão que deveria ter. O bergsonismo tinha levado Bergson para muito longe e, em 1932, não dava oportunidade para novos triunfos.

Eis a primeira interrogação de BERGSON, rememorando os atos infantis: - por que obedecemos? A obediência dr:corre de uma relação social. A obediência começa no meio familiar e se projeta, dentro de um equilíbrio hierárquico, na sociedade.

O princípio de coexistência formúla um sistema de obediência e de comando, que se aproxima do sistema natural que fixa o ordem nas coisas.

Mas a sociedade humana é uma organização e não um organismo, principalmente porque o homem tem predicados decorrentes de sua originalidade. "Cada homem, diz Bergson, pertence à sociedade como a si mesmo. Enquanto sua conciência, que trabalha na profundeza, lhe revela, à medida que se aprofunda, uma personalidade cada vez mais original, incomparavel às outras, pela superfície é, entretanto, a continuidade de outras pessoas que se lhe assemelham, que a ele se unem numa dependência recíproca" (pág. 7).

Bergson procura, então, mostrar o equilíbrio da personalidade dentro da imensa vaga social e lembra, para fixar 
o seu pensamento, a situação das plantas aquáticas que, batidas pelo vento, se ajuntam em defesa, mas essa defesa provém, com muito mais firmeza, de suas raizes, profundamente plantadas na terra. Assim os homens, para a sua defesa unem-se pelo princípio de solidariedade. Mas essa solidariedade que está na superfície, não tem a resistência da raiz social, plantada na profundeza do sêr. "A obrigação que nós compreendemos como um laço entre os homens, liga, inicialmente, cada um de nós, a nós mesmos" (pág. 8).

Erro portanto, para êle, uma moral social que olvidasse uma moral individual. A atitude social, que é de superfície, liga-se à atitude individual, que é de profundidade e assim a solidariedade social aparece quando o "eu social" se reajusta ao "eu individual".

Erro tambem seria desdenhar esse "eu social", porque, de modo algum, o homem pode isolar-se. Mesmo Robinson, em seu isolamento, conserva presente, seu "eu social" BERGSoN, lembra o guarda florésta referido por KIPLING, só, em sua casinhola, numa floresta da India. Todas as noites, vestia sua roupa preta para jantar, "a-fim-de não perder, em seu isolamento, o respeito de si mesmo"

Eis porque a sentimento moral provém de fontes profundas. $O$ criminoso precisa ser encarado, por isso mesmo, com o maior cuidado. O seu problema não é só de utilidade social, não decorre só do exame de dados psicológi$\cos$ ou antropométricos. Ha, no criminoso, algo que transcende, que provém da composição da personalidade humana, que se transfigura pelo desequilíbrio entre o "eu social" e

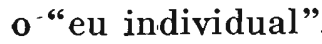

Todo drama moral, todo ato censuravel, toda atividade humana arbitrária decorre desse desequilíbrio.

A adaptação social faz-se normalmente, sem esforços, assegurada pelo hábito, e a sociedade oferece ao indivíduo elementos intermediários a-fim-de facilitar ainda mais essa adaptação. "Temos uma família, diz Bergson: exercemos um mistér ou uma profissão; pertencemos à nossa comuna, 
ao nosso bairro, ao nosso departamento; onde a integração do grupo na sociedade é perfeita, basta-nos agir, cumprir a nossa obrigação para com o grupo a-fim de que estejamos quites com a sociedade. Ela ocupa a periferia: o individuo está no centro. Do centro à periferia, círculos concêntricos, cada vez maiores, envolvem os grupos aos quais os indivíduos pertencem. Da periferia ao centro, a medida que o círculo se restringe, as obrigações se aproximam e o indivíduo encontra-se finalmente, em face de seu semelhante". Sem percebemos bem, vamos aceitando as exigências sociais que traçam ao indivíduo o programa de sua vida quotidiana (pág. 2).

Nessa sociedade que se movimenta, quasi que automaticamente a ponto do individuo pouco perceber as suas determinações, ha momentos em que a conciência aparece e o indivíduo exita. $O$ indivíduo tem que fazer um esfôrço sôbre si mesmo. E' nesse caso que a obediência é, para o indivíduo, um ato de resistência às suas tendências.

A conciência aparece, neste ponto para Bergson, como a própria mudança de estação - é um estado de alarma. como a dor que se sente numa crise de reumatismo. "Temos, diz êle, milhares de obrigações especiais, para as quais, cada um reclama uma explicação. Mas, ha obrigações que tomam aspeto expcional que encontram a nossa resistência, que é ao mesmo tempo, uma resistência à sociedade e a ao próprio "eu individual, que produz um estado de tensão ou de contradição" “Para resistir à resistência, escreve BERgson. nara mantermo-nos o caminho reto, quando o desejo, a paixão ou o interesse nos perturbam, nós devemos. necessariamente. dar razão a nós mesmos" Nesse momento, ao opormos um desejo lícito a um ilícito, isso se não faz senão por um apêlo a uma idéia, mesmo porque "a essência de uma obrigação é uma coisa diferente da exigência da razão"

Em regra agimos por hábito. Não ha na normalidade social, um imperativo categórico, no sentido que Kant lhe atribuiu. O hábito é social e psicológico, ao mesmo tempo, 
porque ele é, no inicio, uma atividade inteligente, que se encaminha para a imitação do instinto. E só assim que se explica, como imperativo, o "il faut parce que il faut".

Bergson, dentro do quadro de sua própria visão filosófica, acha evidente que a sociedade mais natural é a de tipo instintivo. A sociedade humana é movimentada pelo instinto e a inteligência, tendo ambas. como escopo, a utilização de instrumentos.

Considerando a estrutura social, Bergson procura fixar as linhas básicas de sua sociologia: "Humana ou animal, escreve ele, a sociedade é uma organização; ela implica uma coordenação e geralmente tambem uma subordinação de elementos, uns aos outros: of erece, por isso, ou vivido simplesmente ou, de mais das vezes representado, um conjunto de regras ou de leis. Mas em uma colméia ou em um formigueiro, o indivíduo é limitado em sua atividade por sua estrutura e sua organização é relativamente invariavel, ao passo que a sociedade humana é variavel, aberta a todo progresso. Daí resulta que, nas primeiras, cada regra é imposta, necessariamente, pela natureza; ao passo que, nas outras, uma só coisa é natural, a necessidade de uma regra" (pág. 22).

A distinção entre sociedade fechada e sociedade aberta é, para Bergson, fundamental, pois ela explica certos rumos sociais. "O homem, diz ele, saindo das mãos da natureza, é um sêr inteligente e sociavel; sua sensibilidade, é calculada para alcançar pequenas sociedades e sua inteligência é destinada a favorecer a vida individual e a dos grupos. Mas, dilafando-a a inteligência, pelo seu próprio esfôrço, teve um desenvolvimento inesperado, num esfôrço para, pela naturezanaturada, chegar-se à natureza naturante.

Estudando as sociedades abertas e fechadas, a moralidade aberta e fechada, Bergson leva-nos à idéia da justiça. "Esta, diz ele, sempre evoca as idéias de igualdade, proporção e compensação. "Pensare", de onde derivam compensação e recompensa, quer dizer - pesar; a justiça é representada por uma balança. Equidade significa igualdade. Régra e regulamento, retidão e regularidade são palavras que 
designam a linha reta. Essas referências à aritmética e à geometria são carateristicas da justiça, atravéz do desenvolvimento de sua história. Nas obrigações, nos contratos, nas punições primitivas, tais como a "vendetta" decorrem desse esfôrço pela igualdade (pág. 68). Depois, pela amplitude das relações sociais, a justiça se transforma, porém sempre fiel às suas origens mercantis"

Bragson demóra-se neste assunto. Configura vários aspetos da justiça, formúla hipóteses a respeito e lembra que IsaIAs poude pensar numa justiça universal, porque IsraEL, distinguido por Deus, ligado a Deus por um contráto, elevase tão alto, acima do résto da humanidade que, cêdo ou tarde, seria tomado por modêlo. $\mathrm{E}$, depois de anunciar o progresso havido, escreve: "Define-se, comumente, o progrésso da justiça por uma marcha para a liberdade e para a igualdade"

Mostra, porém, a dificuldade prática que existe na formulação dessa liberdade ou dessa igualdade. O certo porém é que a verdadeira liberdade social pode decorrer do consentimento; porque, diz Bergson, "o sacrifício desta ou daquela liberdade, se ela é levemente consentida pelo conjunto dos cidadãos, - é ainda liberdade.

Nesse esfôrço entre o impulso e a resistência, passa pela atividade social, aquilo que é do grupo e aquilo que é individual. Assim, como nota Maud Dandeu o que distingue a sociedade animal é o seu carater "personalista" (7).

Mantendo esse personalismo que dá carater específicin à sociedade humana, o homem, para Bergson, não passa da sociedade fechada, que é a cidade, para a sociedade aberta, que é a humanidade pelo alargamento da primeira. São sociedades de essência diferente. Em vista dos carateres dinâmicos que apresentam e pelo sentido personalista de sua composição, elas assumem proporções inesperadas.

Enquanlo na sociedade animal predomina o determinismo do instinto e o gregarismo estático. na sociedade humana

7) Y-a-t-il un seul entre cité et humanité?, pág. 204, ("Archives de Philosophie du droit, etc.", 1-2-933). 
predomina o indivíduo em si. Por isso mesmo. quanto mais perfeita a sociedade animal, menos seus componentes individuais podem intervir, ao passo que a sociedade humana, ao contrário, ela será mais perfeita quanto mais se acentúa a atividade pessoal, ou como lembra DANDIEU (8) predomina a vontade da pessoa humana, sua iniciativa, seu sentimento de responsabilidade.

A sociedade humana realiza, assim, vários caminhos, longe dessa luta cruel que nos of ereceu os doutrinadores, depois de. HEGEL. dando-nos um trágico carater dialético à verdade social. O conflito, para BERGSon, efetiva-se pela oposição entre a sociedade aberta e a sociedade fechada.

A política não é propriamente uma luta pelo poder, nem uma luta de classes, mas uma luta pela liberdade e pela justiça. Eis porque nasce, para Bergson, a democracia, que é o resultado de uma longa e atribulada experiência humana. Ela é, de todas as concepções políticas, a que mais se afasta da natureza, "a única que transcende. em intenção, ao menos, às condições da "sociedade fechada" Ela atribue ao homem direitos inviolaveis. Esses direitos, para permanecerem inviolaveis, exigem da parte de todos uma fidelidade inalteravel para com o dever. Para ela. existe um homem ideal. cheio de respeito para com os outros. como para consigo mesmo. Essa democracia teórica, que proclama a liberdade, reclama a igualdade e reconcilia essas duas irmãs inimigas, parece provir de uma essência evangélica e traz. de fato, consigo, algo de origem religiosa.

E no seu aspéto dinâmico e racional, a democracia marcha no sentido inverso ao da natureza.

Atravéz dessa febril complexidade social, de seus avanços e artifícios é que Bergson assinala a crise contemporânea. Escreve então: - "Teremos, assim, progresso e oscilação e progresso por oscilação. $\mathrm{O}$ mundo, que aspira o confôrto, passa hoje por um grande desconfôrto" Carrel nada mais fez que comprovar a assertiva de Bergson. Mas o mestre. na tarde de seu pensamento, quando vê o espetáculo de um

(8) Dandieu, obr. cit., pág. 210. 
mundo anarquizado e diminuido, acha que devemos ainda não desesperar, aguardando um futuro social, tocado pela simplicidade, que o demasiado intelectualismo dos nossos dias, não poude oferecer. A ciência, sem sair de sua esfera, poderia auxiliar a humanidade nesse sentido. Depois de mostrar a posição do espírito em face do monstruoso desenvolvimento industrial do mundo moderno, em consequência do emprêgo do combustivel, do carvão, do ferro, da ulha branca e das necessidades místicas da vida, afirma: "A humanidade geme, meio destruida, sobre o pêso do progresso que ela mesmo fez. Ela não sabe bem ainda que o seu futuro só dela mesmo depende".

A obra de Bergson sugere e, ao 'mesmo tempo focaliza, vários problemas sociais. A atividade do homem, da família, dos círculos sociais, da cidade e da humanidade. Ela procura impedir que, na civilização exgotada, a humanidade, entregue a um racionalismo superficial e a um materialismo duvidoso, perca suas ultimas reservas humanas.

A sociologia de Bergson não é, como a de Durkheim, um estudo dos fatos sociais, como coisas. Ela vem das camadas profundas da vida, tendo em conta a vida do nosso mundo, tendo em conta a vida do nosso planeta refratário e a do próprio universo, que "é uma máquina fabricadora de deuses"

Na unilateralidade da sociologia contemporânea, que vê círculos sociais, mecanismos sociais, a sociedade como um monstro absorvente e insaciavel, - BERgson projeta seu pensamento como uma luz propícia - para mostrar, no jôgo da vida, a poderosa resistência da personalidade humana.

Nessa transfiguração do pensamento de Bergson, vêmolo, erguendo, ao lado do marxismo revolucionàrio, do burguesismo materialista e decadente, a sociologia para o plano espiritual. "Il n'y a de réel que ce qui dure", escreve Lous GiLlet (9). "Il n'y a de vrai que l'éternel"

Na movimentação incessante da vida, BErgson percebe a luta do homem pelos valores de raizes misteriosas.

(9) Louis Gillet, “L'Enseignement crétien”, abril, 1933. 
"Vamos além, sem dúvida, confessa Bergson, das conclusões da "Evolução Creadora" Pretendiamos permanecer, o quanto possivel, fieis aos fatos. Nada diriamos que não pudesse, um dia, ser confirmado pela biologia. Certos dessa confirmação, obtivemos resultados que o método filosófico, como o compreendiamos, nos autorizaria a tê-los como verdadeiros. Aqui, ficamos no plano da verosimilhança. Não nos cançamos, porém, de repetir que a certeza filosófica comporta graduações, que ela apela para a intuição, ao mesmo tempo que ao raciocínio, e que se a intuição aplicada à ciência, é sucetivel de ser mantida, essa não pode ser outra que a intuição mística. Com efeito, as conclusões que apresentamos naturalmente completam, muito embóra não seja indispensaveis. os trabalhos anteriores". Uma energia creadora, conclúe BErgson, que seria amor e que aspire tirar de si mesma entes digno de serem amados, poderia semear os valores creadores e fecundos, capazes de repor a vida em seu caminho.. 